\title{
Queue less Shopping Cart with the Self Checkout
}

\author{
Durga Prashat ${ }^{1}$, Kavya Shree.K ${ }^{2}$, K. Shyamala ${ }^{3}$, Sowmya.C ${ }^{4}$, Sonia Maria D'souza ${ }^{5}$ \\ Student, Dept of CSE, Cambridge Institute of Technology, Bangalore, India ${ }^{1,2,3,4}$ \\ Assistant Professor, Dept of CSE, Cambridge Institute of Technology, Bangalore, India ${ }^{5}$
}

\begin{abstract}
In general the shopping and billing of each and every products or a commodity is done by scanning the Barcode or the QR code which is present on the tag of each commodity. Here our concern is about the customer who love shopping but are frustrated by the long queues at the billing counter, this absolutely waste of time and if the particular product is not available at the shopping center the customer have to move to another shopping destination which again increases the time complexity and there is also increase in the Traffic as user have to travel again and the parking problem. In this paper we have come up with an Android application. The application helps the user and the retailer in the easy shopping and reducing the conjunction at the billing area.
\end{abstract}

Keywords: Mobile Communication, QR code scanner, Wifi, Semantics, User Interface.

\section{INTRODUCTION}

As the technology grows there is lot of improvement in living standards of the society. Shopping is become like the hobby of the people. When it comes to name of shopping most prefer the online shopping, there are so many ecommerce shopping sites EX: Flipkart, Amazon, E-bay, Lime-Road, Snapdeal and many more, which use the virtual shopping cart.

The Shopping cart software keeps track of what the user selects to buy from the website before proceeding to the "checkout". An online shopping cart consists of three parts:

1. Product Catalogue

2. Shopping List

3. Checkout System

There online payment or through credit or debit card, and many go with cash on delivery. With this there is Secure Server, as servers is the backbone of the Internet as well as these shopping websites. There is also payment gateway, it is a separate service - it links the shopping cart to the financial networks involved with the transaction.

With the above information we know how the online shopping is done but everyone does not prefer online shopping. People do love shopping in the malls/Shopping Centre, but they have to wait in the long queues for billing, where there are only few billing counters and one person at each counter billing thousands of products by scanning the Bar code or QR code, thus with the same barcode scanning and billing we have come up with the new mobile application which scans the Bar code of the products.

And automatically does the billing and at the end a QR code is generated of the total bill. The user can just scan that code pay the bill and walk out.

Easy shopping is done but not the easy billing. The reality today is that most stores conduct inventory twice per year, not twice every day. Why? Because it's too expensive to hire people to scan bar codes twice daily. As a result, inventory accuracy in most apparel stores is approximately 65 percent-and that means the companies are losing a lot of sales. Well if a user can scan the bar codes by themselves and do a self billing and self checkout there will be increase in the sales.

\section{STATE OF ART}

Perhaps not quite yet, but we are on the way. Tags are getting smaller and smaller and durable that's by the RFID tags.RFID has been present in the grocery sector for a while now, but only on cartons (as pallets and trolleys), with a few exceptions, future store, in Moscow, Russia, is a project run by Rusnano, X5 Retail Group and OJSC RTI, where a store has been piloting item-level RFID on grocery items. The project has been very successful and they hope to do a full roll-out in a store within the end of the year 2013. But for the country like India it is been a tedious task.

When the technology is growing in a higher speed but still there is no move on using it. Well the Government of India setting an objective of creating an awareness about the usage of the technology. Few places the RFID is already in the Big shopping level but not in the Item level, RFID is bit costlier than the Bar code. 


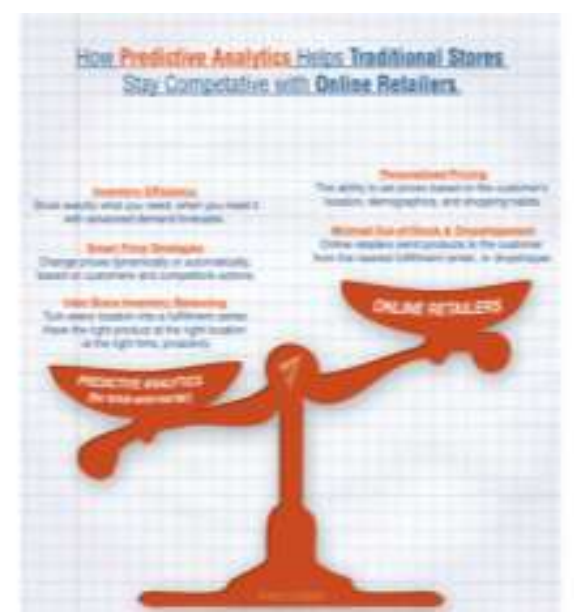

The SAM would, in this case, equal the TAM but only when this project is taken up in the Real-Time environment. At the level of SAM and TAM, If not RFID, what would be the next thing in retail? We say self-scanning barcode systems as it could cumulate item-level RFID completely. The self-scanning system involves handing out mobile devices to customers as they enter a store. The customers can then use the mobile devices to scan barcodes and get additional information about the products and discount offers, as well as gain access to an electronic shopping cart application. Customers scan items as they choose and pick them. The mobile computer gathers a list of the items that is directly used for charging at check-out - thereby, automating the check-out process.

The usage of smart phone in the country like India is increasing, thus using the applications is also is increasing which would help in the online shopping now it can even help in retail shopping by using the smart phone.

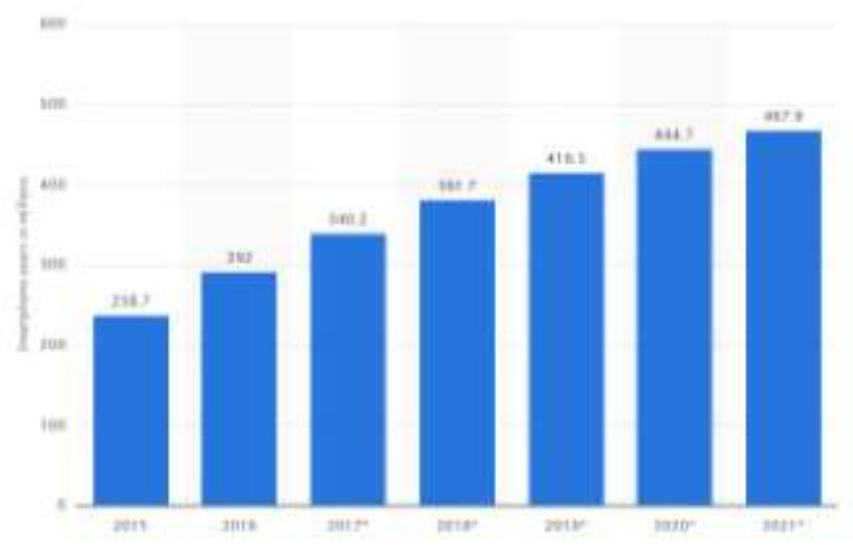

And there is a study made on how much Time do consumers spend during the shopping? It is like Do or Die situation consumer wants to Do shopping but cannot Die for paying the bill by standing in the long Queue.

So let us check how many percentage of waste the precious time based on what platform of shopping like online, stores, mobile, catalog and etc.

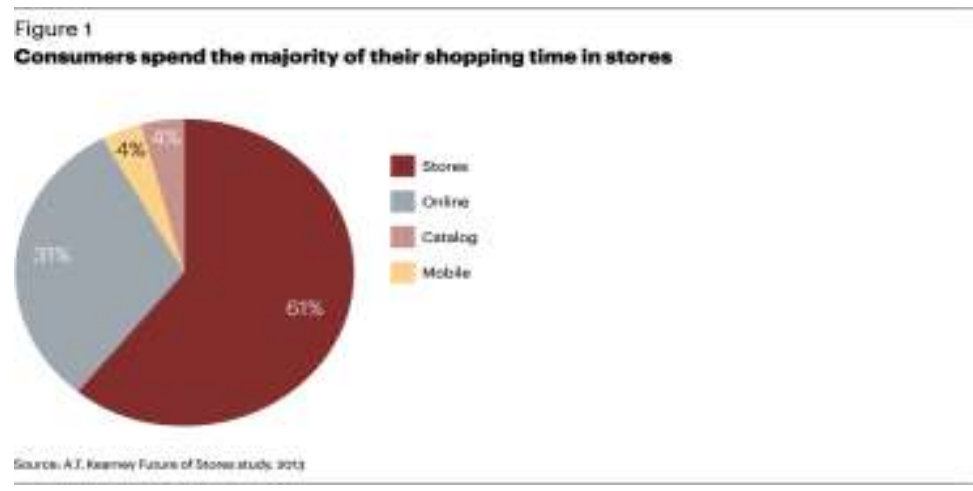


What is the use of the application and how would it help the customers and the retailers? What percent of retail sales attribute to online?

Here is the answer for that:

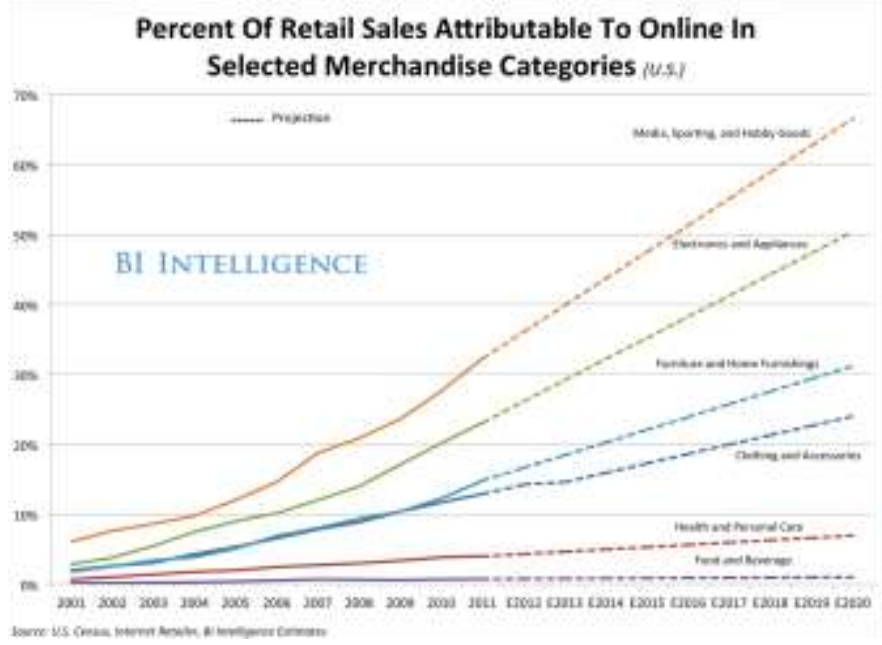

III. RELATED WORK

A. Online shopping carts/E-commerce

The online shopping have the features like:

Store Design, Shopping Cart, Product Catalogue, Payment processing options, Product Promotion, Order Processing, Website analytics and reporting features.

B. Smart shopping using RFID

The "Intelligent Shopping Cart" is developed to assist a people in everyday shopping in terms of reduced time spent while purchasing a product at the best price available.

This system consists of 3 key components/modules

(a) Server Communication component (SCC)

(b) User Interface and display component (UIDC)

(c) Automatic billing and Inventory management component (ABIMC).

The usage of RFID technology is used for the automatic product identification inside the shopping cart thus eliminating consumer intervention in the process of product reading for payment. Each product must have RFID tags and each shopping cart must have an RFID reader.

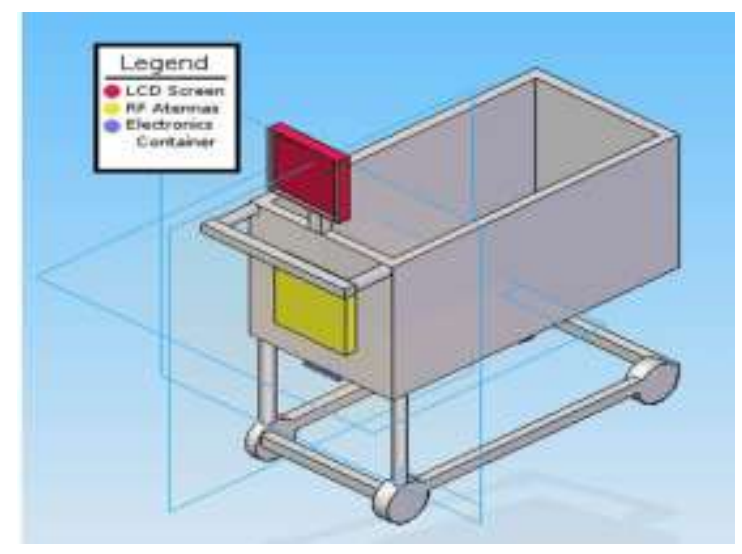

The reader must be able to identify products down to the floor, as there are trolleys where you can place items from $20 \mathrm{~cm}$ above the ground and to about 1,5 $\mathrm{m}$ higher or above than the holder/handle bar since there are both tall products and excessively filled carts. The RFID reader should be able to read all the tags no matter what kind of material or product.

The problem or concerns with RFID are: 
- Since the consumer of an item will not necessarily be aware of the presence of an RFID tag, the tag can be read at a some distance without the knowledge of the user, it becomes possible to gather sensitive data about an individual without consent other.

- If a tagged item is paid for by credit card or loyalty card, then it would be possible to indirectly deduce the identity of the purchaser by reading the globally unique ID of that item (contained in the RFID tag). This is only true if the person doing the watching also had access to the loyalty card data and the credit card data.

C. Digital shopping using NFC

Near-field communication (NFC) is like the set of communication protocols that enable communication between two electronic devices, one of which is usually a portable device such as a smart phone, to establish communication by bringing them within $4 \mathrm{~cm}$ of each other.

NFC is a set of short-range wireless technologies, NFC always involves an initiator and a target.

NFC is the only one technology, with Bluetooth and RFID just as able to strike-up a conversation between two gadgets, but there are distinctions within NFC, too.

They are used in Bootstrapping other connections, Social networking, Gaming etc.

\section{All time shopping using Barcode}

Shopping is in the blood of all the people, everyone walks into the big shopping malls for shopping and passing time.

Most big shopping malls experienced reconstruction and scale expansion. Currently, shopping malls are bigger with more abundant goods and more variety of wares. People are in the pursuit of high quality consumer goods.

To solve the difficulty in customer shopping, large stores have launched a mall layout map, Touch Mall shopping system, and other shopping guide etc.

So let us talk about the product or the item which we purchase, each item will have the Barcode/QR code.

Barcode is an optical code, machine-readable, it represents the data, data generally describes more about the object or commodity that carries the barcode. Originally barcodes systematically represented data by varying the widths and spacings of parallel lines, and may be referred to as linear or one-dimensional (1D). Later two-dimensional (2D) codes were developed, using rectangles, dots, hexagons and other geometric patterns in two dimensions.

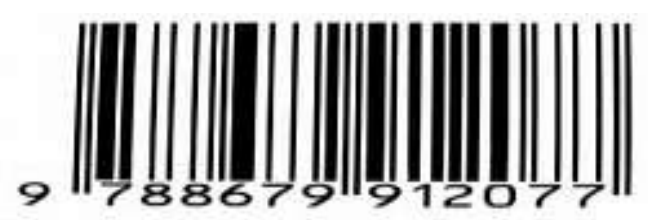

QR code ( Quick Response Code) is the trademark for a type of matrix barcode (or two-dimensional barcode).

A QR code uses four standardized encoding modes (numeric, alphanumeric, byte/binary, and kanji) to efficiently store data. It consists of black squares arranged in a square grid on a white background, which can be read by an imaging device such as a camera, and processed using Reed-Solomon error correction until image can be interpreted.

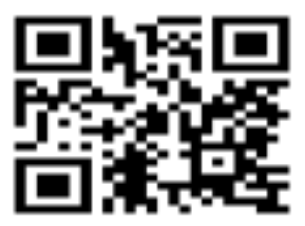

\section{GENERIC ARCHITECTURE (PROPOSED MODEL)}

We are proposing a system which make use of the present technology without any extra payment or wasting time in the long queues.

It is the mobile application which helps you scan the products when the customer purchasing he or she can scan the product by themselves before putting into the cart. Its like the self scan of the products before going to the billing counter. Rather than going to the billing counter and waiting for one person to scan all your purchased products, it is better to self scan.

User can do shopping peacefully for longer time than before and at the end of shopping user can go scan the QR code of the total amount of bill, easily pay the money and checkout.

In the design and implementation we have the use case diagram of the design. 


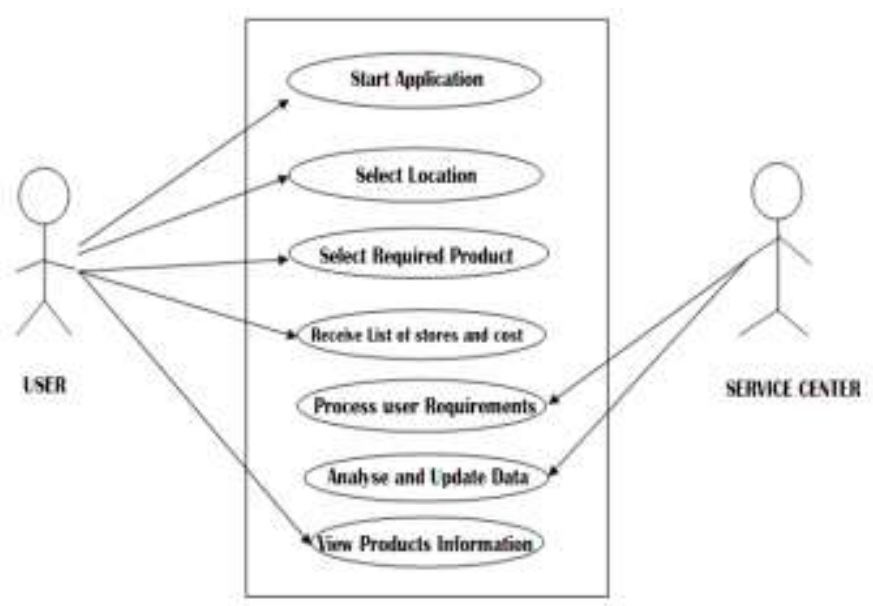

In this application the user have to sign up with the application give the user id and the password.

The application opens the screen in which user have to enter the location in which he can search for the nearby Malls in the particular location, he gets the lets of the malls.

The user can now select the particular mall which he wants to visit. If the user does not know the route to the mall the app itself shows the navigation route to mall. once the user reaches the mall he can find which are the different shops present in the mall.After entering the particular shop he can search for the particular product or the item through the application itself if the item is there it shows where the item is located, else it will not.

In general everyone does the budget planning, money is very much important to all while shopping also the laymen keeps the budget, thus we have a budget planner included in the application.
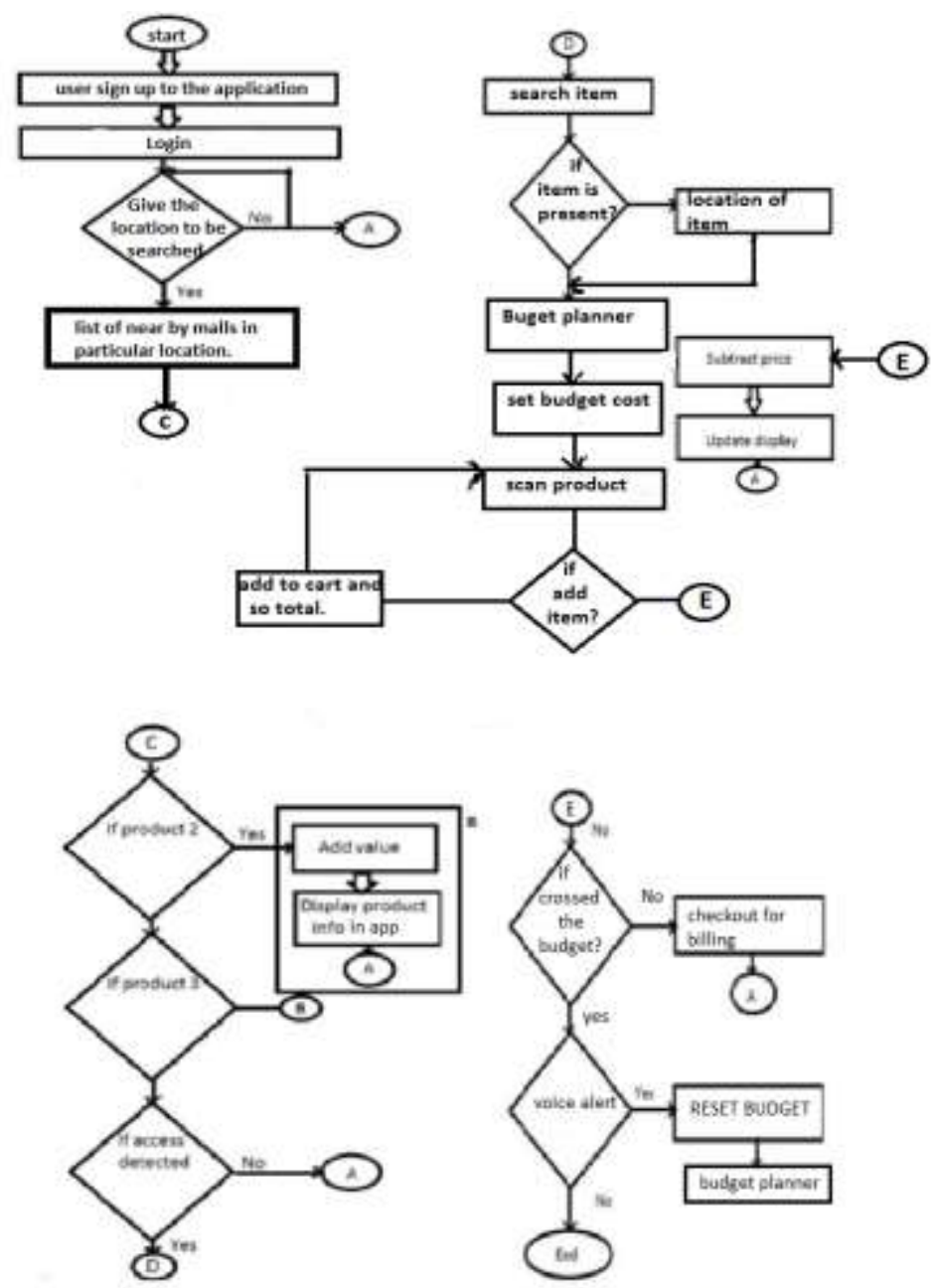
User can set the budget and then start shopping, if the user crosses the particular set budget the application gives the sound alert saying you have crossed the budget and showing the option RESET the budget or checkout. Now the user RESET the budget and start shopping again or walk to the billing counter to checkout At the end of shopping the application generates the QR Code for the bill total, the user can just scan the total (QR code) pay the money and just walkout.

\section{CONCLUSION}

The application helps the user to self scan the products he / she is purchasing, check for the manufacture and expiration date, do the budget planning which helps save money, self billing without any long queues and the application shows the navigation to the mall and gives the information about the all the products.

As barcode is the simplest way to find out the product information and which is less cost and which is used world widely in all the products, rather than waiting someone else to scan and bill the product we can self scan and bill the items.

\section{REFERENCES}

[1] Seeing-is-believing: using camera phones for human-verifiable authentication J.M. McCune; A. Perrig; M.K. Reiter

[2] E-SmallTalker: A Distributed Mobile System for Social Networking in Physical Proximity Zhimin Yang; Boying Zhang; Jiangpeng Dai; Adam C. Champion; Dong Xuan; Du Li

[3] A General Scheme for Extracting QR Code from a Non-uniform Background in Camera Phones and Applications Yu-Hsuan Chang; ChungHua Chu; Ming-Syan Chen

[4] http://www.rfidjournal.com

[5] http://en.wikipedia.org/wiki/zigbee.

[6] American Time Use Survey, http://www.bls.gov/tus/charts.

[7] D.V.S Chandra Babu, "wireless intelligent billing trolley for supermarket", International Journal of Advanced Research in Technology, vol.3, issue 1, Aug. 2012. 